\title{
Investigations on the attenuation characteristics of blast-induced ground vibrations for developing controlled blast design
}

\author{
VMSR Murthy, NV Bhagade and RK Das \\ Indian Institute of Technology (ISM) \\ Dhanbad, India \\ vmsr_murthy@yahoo.com
}

\begin{abstract}
Drilling and blasting is still the most prolific way to extract minerals and associated waste from the earth, more so in case of hard rocks with uniaxial compressive strength greater than $50 \mathrm{MPa}$. Considering the growing demand for these minerals reducing ground vibrations, air vibrations, fly rocks, dust and back break has become mandatory for successful operation of these quarries and mines. A study has been carried out in one of the quartzite quarries which is surrounded by a village within about $100 \mathrm{~m}-300 \mathrm{~m}$ from quarry line. The study was carried out to understand the nature and directional variation of propagation of blast-induced ground vibration with an aim to control the same by keeping it within the permissible limits of ground vibration as suggested by Directorate General of Mines Safety (DGMS) for various types of human dwellings. The behavior of blast-induced ground vibrations and its frequency response were observed based on different variables (viz. scaled distance, direction of propagation of seismic waves, and degree of development of benches). A model consisting of two components (viz. mid-field and far-field) and its superiority and applicability over a combined equation of PPV is also discussed. Further, the directional effect of blast vibrations and the influence of degree of development of benches on the ground vibration is also outlined. This paper synthesizes the results of the abovementioned investigations and reports the development of a ground vibration prediction approach for safe and productive rock excavations in quarries and mines.
\end{abstract}

Keywords-attenuation, PPV (peak particle velocity), frequency, scaled distance.

\section{INTRODUCTION}

Ground vibrations persist as one of the major impediments in smooth running of drilling and blasting operations. On one hand, good fragmentation is demanded for better machine productivity and output and on the other hand ground vibration needs to be monitored and minimized both for the sake of the safety of proximal structures and improvement on further round of blasts. Such a situation often results in a compromise in quantity of charge per delay affecting fragmentation due to a generalized ground vibration predictor equation covering far-field and mid-field data. Generally, bench blasting is restricted within $100 \mathrm{~m}$ of human habitat and in rare cases it moves within $50 \mathrm{~m}$ to $100 \mathrm{~m}$ with an advanced blasting technology such as electronic detonators, safe charges and complete muffling. The various regulatory bodies which govern the activities in mines and quarries have stipulated the limits of vibration (in terms of PPV for various frequency ranges).

The various models for predicting PPV as developed by past authors are presented in Table I: As the charge detonates, the blast waveforms depicting peak particle velocity (PPV) values and frequency curves are registered using the seismograph units. A certain scaling law is chosen (from Table I) relevant to the blast situation. This is followed by regression analysis on the recorded data and thus a suitable model for predicting the blast vibration is developed. This becomes the basis for proposing a suitable blast design for safe blasting.

This predictor equation is used to calculate the maximum charge per delay for a certain blast situation complying with the DGMS limits of maximum PPV (peak particle velocity) and frequency range in which the waves lie. The DGMS stipulates the maximum permitted PPV for various frequency classes as given in Table II. While the explosive is getting detonated (i.e. while the detonation wave travels through the explosive column and gradually as the VOD reaches steady state) rock crushing sets in. This crushing is brought about by shock energy of the explosive.

Rock crushing is followed by radial fracturing. Eventually, the velocity of crack formation is overtaken by the velocity of the shock waves [13]. The body waves (Compression wave (P-wave) and Shear wave (S-wave)) and the surface waves (Rayleigh, Love, Channel and Stonely waves) travel for certain distances in an attenuating fashion. It is these waves that create disturbances in the ground (hence the term ground vibration) in three different directions (viz. transverse, longitudinal and vertical) and get recorded in the seismograph units placed at pre-decided monitoring station. The seismograph units record the vibration signatures in terms of PPV (peak particle velocity) and frequency $(\mathrm{Hz})$ values.

\section{BLAST- INDUCED ViBRATION PREDICTION AND ATTENUATION}

The attenuating nature of the wave is attributed to the fact that both the amplitude and shape change as it travels further from the blast source. The reduction in amplitude is caused by the following four reasons [10]: 
- Geometric spreading

- Dispersion

- Reflection at surfaces differing in acoustic impedances

- Damping

The most prevalent method of studying the attenuation characteristics of a wave is the scaled-distance approach (as shown in Table I). It is stated mathematically as

$$
S D=R / Q_{\max }^{a}
$$

where, $\mathrm{SD}=$ scaled distance, $\mathrm{Q}_{\max }=$ maximum charge per delay $(\mathrm{kg}), \mathrm{R}=$ distance from the blast $(\mathrm{m}), \mathrm{a}=$ degree of scaling

TABLE I: SOME OF The GRound Vibration PREDiCTOR MOdELS DEVELOPED

\begin{tabular}{|c|c|c|}
\hline Sl. No. & $\begin{array}{l}\text { Predictor Model } \\
\text { Name }\end{array}$ & Equation \\
\hline 1 & $\begin{array}{l}\text { USBM (Duvall and } \\
\text { Fogelson, [7]) }\end{array}$ & $v=k\left(\frac{D}{\sqrt{Q_{\max }}}\right)^{-\beta}$ \\
\hline 2 & $\begin{array}{c}\text { Ambraseys-Hendron } \\
{[1]}\end{array}$ & $v=k\left(\frac{D}{\sqrt[3]{Q_{\max }}}\right)^{-p}$ \\
\hline 3 & Indian Standard [4] & $v=k\left(\frac{Q_{\max }}{D^{2 / 3}}\right)^{\beta}$ \\
\hline 4 & $\begin{array}{l}\text { Langefors- } \\
\text { Kihlstrom[11] }\end{array}$ & $v=k\left(\sqrt{\frac{Q_{\max }}{D^{2 / 3}}}\right)$ \\
\hline 5 & Holmberg-Persson [9] & $v=k \times Q_{\max }^{a} \times D^{b}$ \\
\hline \multirow{2}{*}{6} & Ghosh- Daemen[8] & $v=k\left(\frac{D}{\sqrt{Q_{\max }}}\right)^{-\beta} e^{-\alpha D}$ \\
\hline & Ghosh-Daemen[8] & $v=k\left(\frac{D}{\sqrt[3]{Q_{\max }}}\right) \quad e^{-\alpha D}$ \\
\hline 7 & CMRI [12] & $v=n+k\left(\frac{D}{Q_{\max }}\right)^{-1}$ \\
\hline 8 & $\begin{array}{c}\text { Chakraborty, Murthy } \\
\text { \&Jethwa[5] }\end{array}$ & $v=\frac{K Q^{\alpha}}{D^{n Q^{\beta}}}$ \\
\hline
\end{tabular}

The reason for such attenuation law is that it encompasses the two variables that control the value of PPV viz. distance and maximum charge per delay (or maximum charge detonated at a time). Usually, in investigations a cylindrical explosive geometry is assumed for long cylindrical charges (Duvall and, [7]) and the PPV is estimated from the generalized predictor equation given below:

$$
v=k\left(\frac{D}{\sqrt{Q_{\max }}}\right)^{-\beta}
$$

where, $\mathrm{k} \& \beta$ are site constants determined from regression analysis.

However, the predictor equations proposed by different authors utilize square root scaling as well as cube root scaling depending upon the scaling effect of distance of monitoring and charge configuration.

TABLE II: THE DGMS COMPLIANCE CRITERIA FOR VARIOUS BUILDINGS FOR

\begin{tabular}{|c|c|c|c|}
\hline \multirow{2}{*}{ Type of structures } & \multicolumn{3}{|c|}{$\begin{array}{l}\text { Dominant Excitation frequency, } \\
\text { Hz }\end{array}$} \\
\hline & $<8 \mathrm{~Hz}$ & $8-25 \mathrm{~Hz}$ & $>25 \mathrm{~Hz}$ \\
\hline \multicolumn{4}{|c|}{ A) Buildings/structures not belonging to the owner } \\
\hline $\begin{array}{l}\text { Domestic houses/structures } \\
\qquad \text { (Kuchha, bricks \& cement) }\end{array}$ & 5 & 10 & 15 \\
\hline $\begin{array}{l}\text { Industrial building (RCC \& Framed } \\
\text { structures) }\end{array}$ & 10 & 20 & 25 \\
\hline $\begin{array}{l}\text { Objects of historical importance } \\
\text { and sensitive structures }\end{array}$ & 2 & 5 & 10 \\
\hline \multicolumn{4}{|c|}{ B) Buildings belonging to the owner with limited span of life } \\
\hline $\begin{array}{l}\text { Domestic houses/structures } \\
\qquad(\text { Kuchha, bricks \& cement) }\end{array}$ & 10 & 15 & 25 \\
\hline $\begin{array}{l}\text { Industrial buildings } \quad(\mathrm{RCC} \quad \& \\
\text { framed structures) }\end{array}$ & 15 & 25 & 50 \\
\hline
\end{tabular}
DifFERENT FREQUENCY RANGE (CIRCULAR No. 7, 1997)

\section{INFLUENCE OF BENCH STIFFNESS ON BLAST-INDUCED VIBRATIONS}

Ash [2] studied the effect on fragmentation of rock by changing the bench stiffness (ratio of burden to bench height, $\mathrm{B} / \mathrm{H})$. One of the components of rock breakage mechanism is flexural breakage (Pal Roy [13]) of the cantilever beam of length, $\mathrm{H}$ and thickness, $\mathrm{B}$ (Fig 1). The gases contained in the boreholes, after the passage of the shock waves, enter and expand the radial cracks and reach the free face by breaking it by bending or flexure.

Therefore, the fragmentation is based on the breaking of this cantilever beam [6]. When $\mathrm{H} / \mathrm{B}$ ratio is large, it is easy to displace and deform rock, especially at bench center [15]. Ash [3] states that the optimum ratio is

$$
\mathrm{H} / \mathrm{B} \geq 3 \text {. }
$$

Benches in quarries may be classified as: fully developed, partially developed and not developed (in case of solid blasting). In case of fully developed bench, shown in Fig 1, the shock wave and gas waves seek their vents in radially crushed zone and find their way out to the free face thus breaking the bench effectively due to complete reflection. 
But in case of partially developed or undeveloped bench, the gas energy remains trapped inside the rock mass despite of radial crushing by shock wave. Thus, the explosive energy, not finding a free face (or a well-developed cantilever beam) gets transmitted through the rock mass as ground vibrations. Therefore, the intensity of ground vibrations in case of partially developed or undeveloped bench is augmented further by the absence of a free face.

In a fully developed bench, breakage is proper because of proper venting of the gas energy through the cracks produced by shock wave, thus the beam is properly fragmented. But in case of partially developed or undeveloped benches, fragmentation is poor because of inadequate breakage. In the latter case, due to the absence of free face the, there is no reflection breakage; venting of explosion gases is limited, thus yielding big boulders. Presence of big boulders in the ROM influences the yield of mineral as well as the additional bridging at crusher point. Therefore, in benches improperly developed the ground vibrations are high, fragmentation is good but yield is very low. It was observed during the study that about 3 to 4 benches were not fully developed and hence might have contributed to varied ground vibrations leading to scatter of data for the same scaled distance. This needs further analysis.

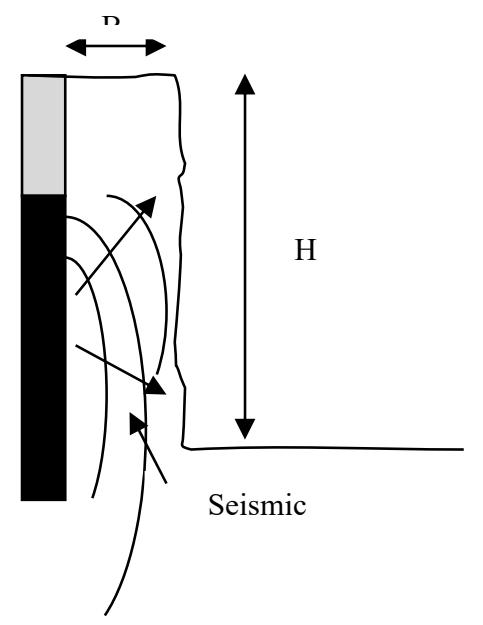

Fig. 1: Fragmentation caused by breakage of cantilever beam

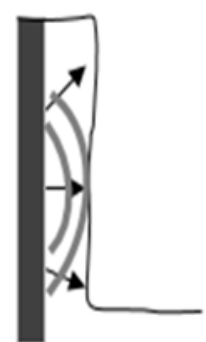

(1)

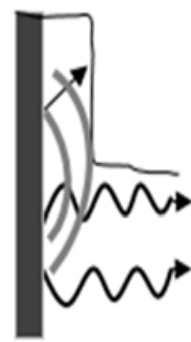

(2)

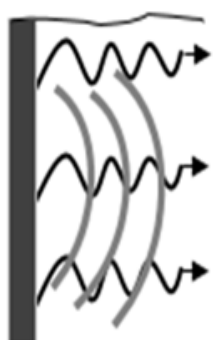

(3)
Fig. 2: Ground vibrations for (1) fully developed bench (2) partially developed bench (3) Undeveloped bench

\section{GEOMETRICAL INFLUENCES ON THE ATTENUATION OF BLAST WAVES}

Wiss\&Linehan[14] report the influence of direction of blast initiation in a surface coal mine blasting. Geophones were placed along three different directions at large but equal distances. The first was placed parallel to the free face but away from the direction of initiation; the second was placed in a perpendicular direction and the third was placed parallel but along the direction of initiation. The ratios of the PPV in the three directions (blast 1, blast 2 and blast 3) were reported as follows:

$$
2<\frac{\text { blast } 2}{\text { blast } 1}<2.5 \& 3<\frac{\text { blast } 3}{\text { blast } 1}<6
$$

The vibrations get influenced by directions because of coupling and from wave addition effects. When shot is initiated in any direction, the intervals between the peaks will be reduced and therefore, there is a greater chance for wave addition (Dowding [6]). Therefore, a nominal delay of $17 \mathrm{~ms}$ between successive delays is suggested to eliminate the addition of vibrations [14].

The directional change in vibration may also be possible because of variations in the strata properties. The blastgenerated waves encounter different rocks with different properties (i.e. of different acoustic impedances) in different directions due to which the different vibration signatures are recorded in different directions at approximately same distances.

\section{EXPERIMENTAL SITE DESCRIPTION}

A study was conducted in a stone quarry which is being re-opened for producing stone chips for the purpose of road /bridge construction for the four laning of a section of NH-83 in the state of Bihar. Expected reserve is 40 Lac MT with a life expectancy of 5 years. The general topography of the mine is hilly with old excavated irregular mine faces and high benches, which require suitable dressing. Mechanized production of rocks, involving deep hole blasting with 6 to 7 $\mathrm{m}$ high benches is practiced. Since the stone mine falls near the human dwellings the mine management was desirous to develop a suitable blasting pattern to control ground vibration, air over pressure and fly rock. The rocks are essentially quartzitic in nature and belong to Satpura Age. The quartzite stones of the area display very well-preserved primary sedimentary structures such as stratification, crossbedding, ripple marks, mud cracks and convolute-bedding. Other minerals comprise of schist, ferruginous phyllite and phyllitic shale.

\section{A. Drilling}

Crawler mounted Down the Hole (DTH) drill of $105 \mathrm{~mm}$ diameter of Atlas Copco make is deployed. General dip of the formations is steep, dipping away from the face. The holes are made vertical with adequate sub-grade drilling for reducing the fly rock and toe formation. Hydraulic Excavators with a boom reach of 9.3 are deployed. PC200 and equivalent with a bucket capacity of $1.2 \mathrm{cu} . \mathrm{m}$. are deployed. 


\section{B. Blasting}

Blasting (during trials) was carried out using cartridged slurry explosives, typically, Aquadyne as primer and Energel as column charge. A ratio of 1:3, for primer to column, was adopted for ensuring sustained detonation and fragmentation. Similar type explosives with proved field performance can be used. About 14 to $23 \mathrm{~kg}$ of explosive was used per hole depending on hole depth, rock formation, free face available and nearness of human dwellings. Effective fragmentation will lead to lesser ground vibration, air over pressure and most importantly fly rock. To ensure safe blasting and adequate fragmentation, bottom hole initiation using NONEL system of firing was adopted. It was found that powder factor during trials varied from 1.0 to $3.1 \mathrm{~m} 3 / \mathrm{kg}$ of explosive depending on formation. Suitable blasting shelter and other accessories such as siren, flags, muffling mats and circuit tester were ensured in accordance with provisions of MMR 1961. Considering the close proximity of dwellings and human occupancy 'a liaison officer' coordinated the blasting operations and human movements at the time of blasting, which was necessary from safety view point.

\section{Blast Design and Monitoring}

The magnitude of blast-induced ground and air vibration were recorded using Minimate plus, Minimate 077and MiniSeis III manufactured by M/s. Instantel, Inc. Canada and M/s White Seismology. The instruments recorded the level of vibration in terms of peak particle velocities in the three orthogonal directions, ground frequencies in the three directions, time of peak occurrence, and peak air over pressure in terms of decibels (linear).

The formations generally are massive with very tight joints requiring suitable blast design for achieving desired fragmentation. Depth of blast holes, in various rounds of blast, varied from 6 to $7 \mathrm{~m}$. True burden varied from 1.5 to $2.5 \mathrm{~m}$ and true spacing varied from 2.0 to $3.5 \mathrm{~m}$. The total charge per round varied from 120 to $625 \mathrm{~kg}$ and the maximum charge per delay varied from 14 to $23 \mathrm{~kg}$. The height of stemming column varied from 3 to $3.5 \mathrm{~m}$. The number of blast holes per round varied from 8 to 27 . Twin detonator (Twindet) shock tube system was used for firing the explosives inside the holes as well connecting the trunk line between hole to hole. The circuit was fired using electric delay detonators and exploder from a safe location with adequate precautions. Wire mesh covered by sand bags was used to cover the blast holes as a muffling measure. From the visual observation of blasts and inspection of site after blasting it was observed that the throw of the muck was contained within $10 \mathrm{~m}$ and the fly rock was also adequately controlled. Fig 3 depicts mine plan showing the location of trial blasts and ground vibration, air overpressure recording stations as well as the final lease boundary position with respect to the human dwellings.

\section{Results of Blasts}

A total of 9 blasts were monitored with multiple seismographs located around the quarry. Sampling frequency was set at 1024 samples per second (sps). Trigger level was set at $0.767 \mathrm{~mm} / \mathrm{s}$. Time-wise plots of seismic vibrations and air overpressures were recorded. Amplitude versus frequency

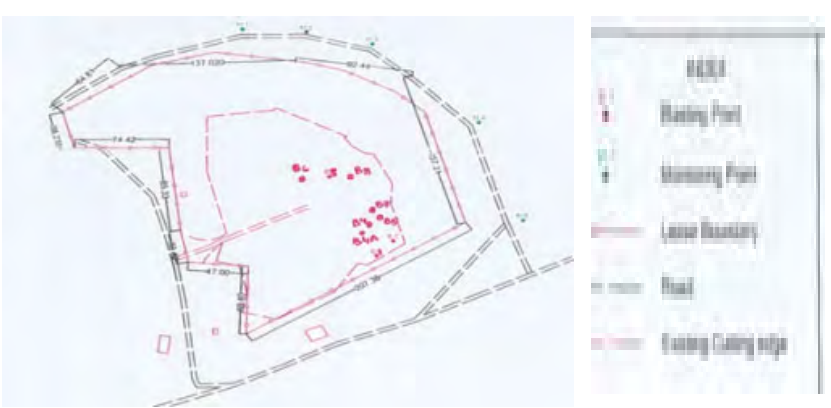

Fig. 3: Mine plans showing the trial blast locations, existing cutting edge, distance between the final lease boundary and the human occupation line

curves were recorded, giving PPV values at dominant frequency. Zero crossing (ZC) frequency and Fast Fourier Transform (FFT) frequency were also calculated from the recorded data. Each hole was carefully charged and timed because of the fact that the maximum charge per delay is the sum of the explosives weight within 8ms delay interval in the entire shot pattern (Hustrulid 1999). Monitoring stations were selected based on the vulnerability of the surface structures. The dwellings around the mine spanned over a distance range of $100 \mathrm{~m}$ to $300 \mathrm{~m}$. Blast, explosive and vibration data were collected for all 9 trial blasts to perform analysis and come out with safe and productive blast designs considering the constraints.

\section{FREQUENCY ANALYSIS}

The velocity components were plotted against frequency components to see if the readings were transgressing the limits stipulated by DGMS (Table II). The plots are shown as follows:

The blue vertical line indicates $8 \mathrm{~Hz}$ and the red vertical line indicates $25 \mathrm{~Hz}$. The plots show that there are no points below $8 \mathrm{~Hz}$ therefore eliminating the chances of buildings getting damaged by low frequencies. In all the PPVfrequency plots highest values of PPV were observed in the frequency range higher than $25 \mathrm{~Hz}$. The DGMS criteria stipulates that for domestic buildings not belonging to the owner the maximum allowable PPV is $15 \mathrm{~mm} / \mathrm{s}$, for frequencies beyond $25 \mathrm{~Hz}$. There are only two points which are marginally crossing this limit. One is $15.4 \mathrm{~mm} / \mathrm{s}$ at a distance of $103.35 \mathrm{~m}\left(\mathrm{SD}=12.42 \mathrm{~m} / \mathrm{kg}^{1 / 2}\right)$ and the other is $18.3 \mathrm{~mm} / \mathrm{s}$ at a distance of $132.5 \mathrm{~m}(\mathrm{SD}=20.62)$. Therefore, it is safely concluded that the domestic buildings are safe range with respect to ground vibrations generated by blasting.

\section{STATISTICAL ANALYSIS OF DATA}

The acquired data were analyzed statistically. Plots for the trends of PPV with scaled distance both for near-field and far-field were obtained. To get a holistic view of the attenuation, the PPV values were plotted against the square root- scaled distances (combined equation) as shown below in Fig 5.

Further, to categorize the attenuation characteristics of the ground vibrations the data set was divided into two 
groups based on scaled distance viz. mid-field and far-field. These two data sets were plotted separately with scaled distance to yield two predictor equations viz. mid-field and far-field. The reason for splitting the attenuation trend is that when the combined equation is observed carefully, the decline of the power curve undergoes a sharp change after a value of scaled distance. As can be observed above, the decline rate of the curve undergoes a slight decrease after a scaled distance of $30 \mathrm{~m} / \mathrm{kg}^{1 / 2}$. The point where the trend of the slope of the curve undergoes a visible change is shown with a green vertical line (Fig 5). The most widely used PPV-predictor model is the USBM model developed by Duvall and Fogelson [7] considers charges to be cylindrical and thus uses square root scaling. The Ambraseys and Hendron [1] model considers spherical charges thus uses cube-root scaling for prediction. It was also observed during regression analysis of the data that the most appropriate scaling laws applicable for mid-field and far-field, as defined earlier are square-root scaling and cube-root scaling respectively. It is assumed here that square-root scaling would be proper for mid-field predictions and cube-root scaling would be proper for far-field predictions considering the scaling effect. As shown in Fig 4, most of the plot points lie beyond the range of $25 \mathrm{~Hz}$ and a few points lie between $8-25 \mathrm{~Hz}$ and no point lies below $8 \mathrm{~Hz}$. Therefore, the maximum charge per delay for various distances (both nearfield and far-field) was calculated using the DGMS stipulated velocity, $15 \mathrm{~mm} / \mathrm{s}$ (for the frequencies $>25 \mathrm{~Hz}$ ) in case of domestic houses not belonging to the owner (Table II). Thus, three equations were obtained using regression analysis and they are compared in Table III:

The maximum charge per delay is calculated using the fitted equation obtained by regression. The above table shows, for the DGMS recommended PPV and distance from the point of blast

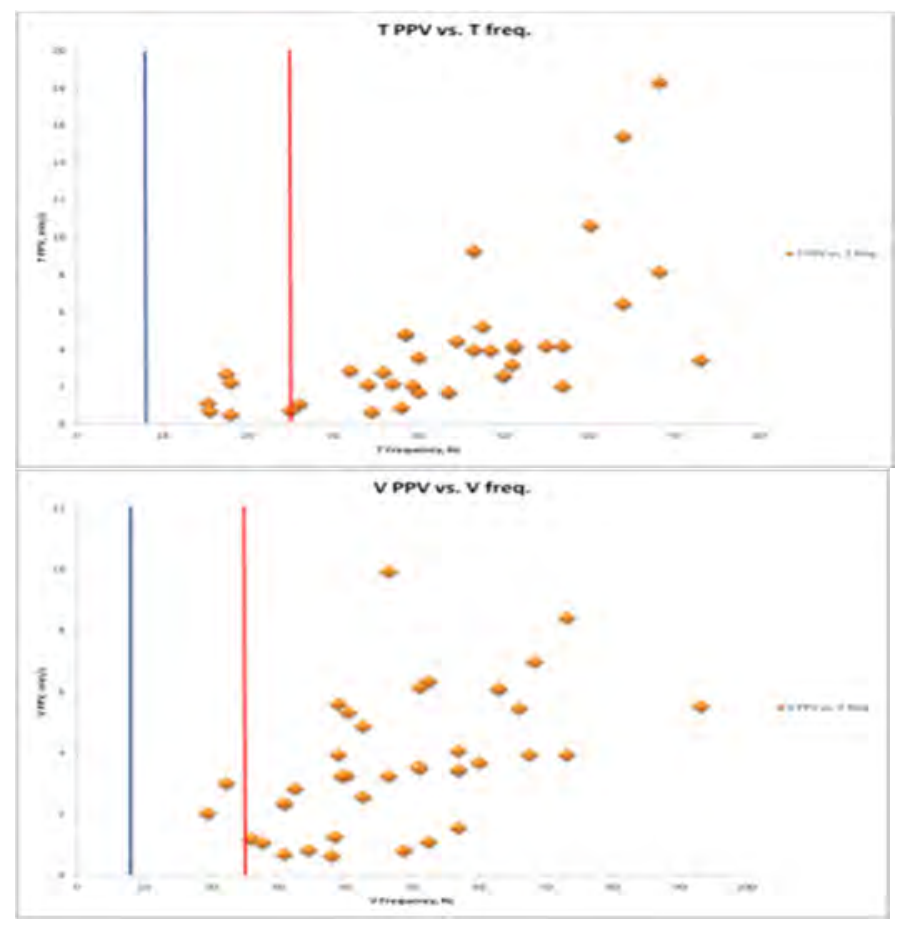

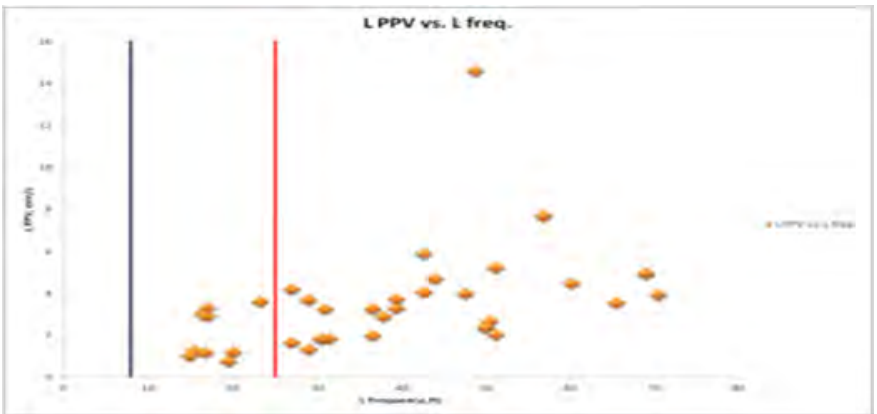

Fig. 4: Plots for DGMS compliance (1) T PPV vs. T frequency (2) V PPV vs. V frequency (3) L PPV vs. L frequency

to structures, the combined equation gives higher values of maximum charge per delay as compared to the mid-field and far-field equations. Therefore, such a bicameral attenuation model (viz. mid-field and far-field) is considered superior for understanding the attenuation characteristics from a safety point of view. The regression $\mathrm{R}^{2}$ values are also superior for the mid-field and far-field equations as compared to the combined equation, indicating better predictive ability. The reasons for lower $\mathrm{R}^{2}$ value for the combined equation are due to directional variation and underdeveloped benches. But since, in the bicameral model as can be observed in Table III, that there is almost a $50 \%$ difference between the recorded and predicted values for the far-field equation; the efficacy of the mid-field and far-field needs to be further examined. This is shown in the table below (Table IV).

Table IV confirms that the mid-field predictor equation proposed for understanding the attenuation nature of ground vibration is more efficient (with less average error in prediction) as compared to the far-field and combined equation. The inference that can be drawn based on this analysis is that prediction of ground vibration based on the combined equation may not be safe when the quarry line comes closer to the structures/dwellings due to higher maximum charge values obtained as explained earlier. This is apart from the errors in prediction of ground vibrations

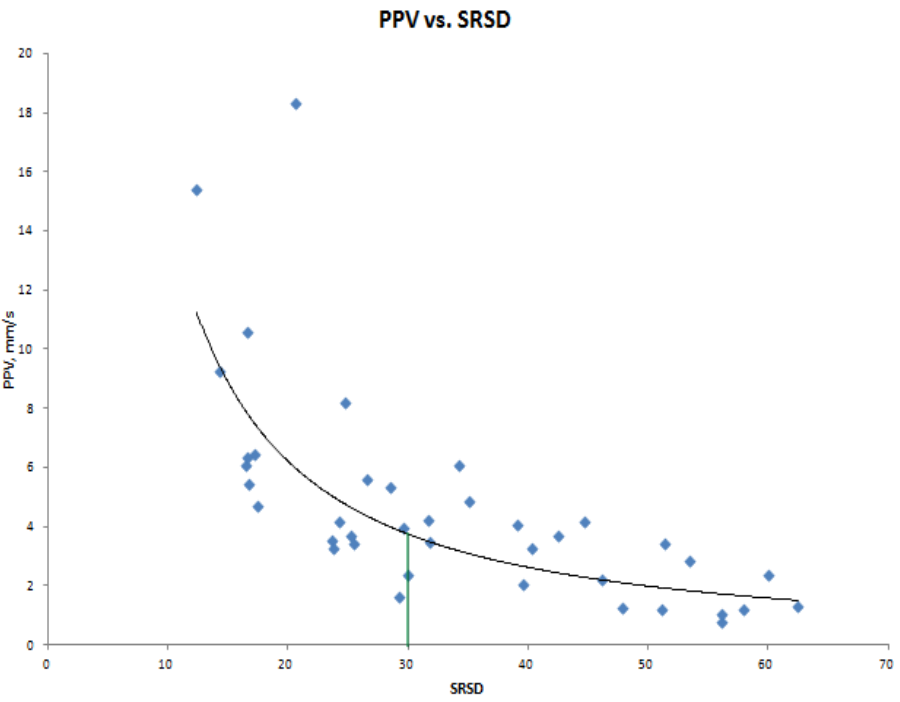

Fig 5: Combined equation encompassing both mid-filed and far-field attenuation 
TABLE III: COMPARISON OF MAXIMUM CHARGE PER DELAY FOR COMBINED, MID-FIELD AND FAR-FIELD PREDICTOR EQUATIONS

\begin{tabular}{|c|c|c|c|}
\hline Parameter & $\begin{array}{c}\text { Combined } \\
\text { Equation } \\
\boldsymbol{R}^{\mathbf{2}}=\mathbf{0 . 6 2}\end{array}$ & $\begin{array}{c}\text { Mid-field } \\
\text { Equation } \\
\boldsymbol{R}^{\mathbf{2}}=\mathbf{0 . 6 7}\end{array}$ & $\begin{array}{c}\text { Far-field } \\
\text { Equation } \\
\boldsymbol{R}^{\mathbf{2}}=\mathbf{0 . 7 3}\end{array}$ \\
\hline \multirow{2}{*}{ Distance, $m$} & 155.7 & \multirow{2}{*}{155.7} & \multirow{2}{*}{198.73} \\
\hline & 198.73 & & \\
\hline \multirow{2}{*}{$\begin{array}{l}\text { Scaled Distance } \\
\text { (original data) }\end{array}$} & 24.26 & \multirow{2}{*}{24.26} & \multirow{2}{*}{80.71} \\
\hline & 51.43 & & \\
\hline \multirow{2}{*}{$\begin{array}{l}\mathrm{Q}_{\max }, \mathrm{kg} \\
\text { (DGMS compliance) }\end{array}$} & 246.64 & \multirow[b]{2}{*}{226.32} & \multirow[b]{2}{*}{224.80} \\
\hline & 401.80 & & \\
\hline \multirow[b]{2}{*}{ Recorded PPV, mm/s } & 4.18 & \multirow[b]{2}{*}{4.18} & \multirow[b]{2}{*}{3.45} \\
\hline & 3.45 & & \\
\hline \multirow[b]{2}{*}{ Predicted PPV, mm/s } & 4.94 & \multirow[b]{2}{*}{4.00} & \multirow[b]{2}{*}{1.73} \\
\hline & 1.95 & & \\
\hline
\end{tabular}

computed using the same equation. This indicates the need of bringing suitable changes in the ground vibration prediction approaches.

TABle IV: COMPARISON OF PERCENTAge ERrors OF COMBINED, Mid-FIELD AND FAR-FIELD EQUATIONS

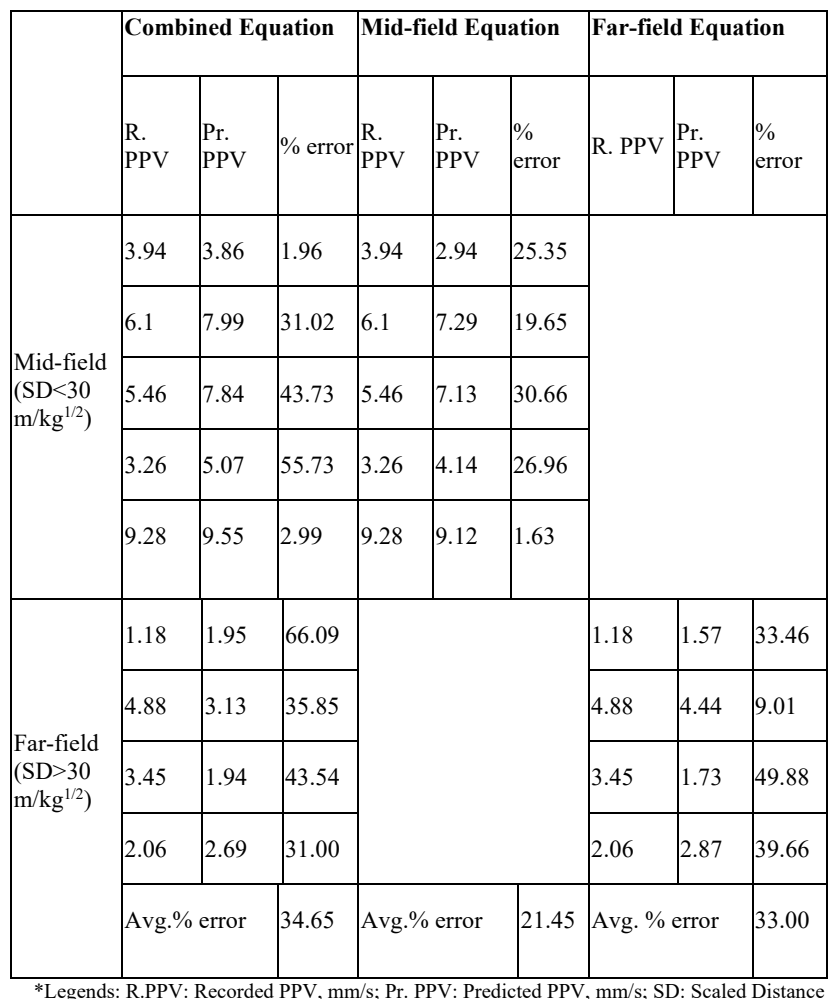

The Fig below shows the regression curves obtained for PPV vs. scaled distance for both mid-field and far-field respectively. It was observed in the data that out of the three components $(\mathrm{T}, \mathrm{V}, \mathrm{L})$ of vibrations the highest values were those of $\mathrm{V}$ (vertical) and L (longitudinal). Therefore, it was believed to be appropriate to show the trends of T, V, L with scaled distance to appreciate the attenuation of waves. Since PVS (Peak Vector Sum) gives a higher estimate of intensity of ground vibrations, it is used where sensitive structures are present. Therefore, it is also believed to be significant in compliance monitoring of ground vibrations.

The plots of the components of ground vibrations $(\mathrm{T}, \mathrm{V}$, and L) and peak vector sum were also analyzed w.r.t. scaled distance both for mid-field and far-field to understand the directional variability.

\section{A. Mid-field}

The trends of regression curves of components of ground vibration versus square-root scaled distance are shown as follows:

It is clear from the trends that the $\beta$ value on an average is higher in case of far-field than in case of mid-field. Therefore, the decline in the trend in case of far-field is sharper as compared to the decline in then trend of midfield. This shows that the rate of attenuation is faster in regions away from the blast (i.e. at scaled distances greater than $30 \mathrm{~m} / \mathrm{kg}^{1 / 2}$ ).

\section{A. Far-field}

The trends of regression curves of components of ground vibration versus cube root scaled distance are shown as follows:

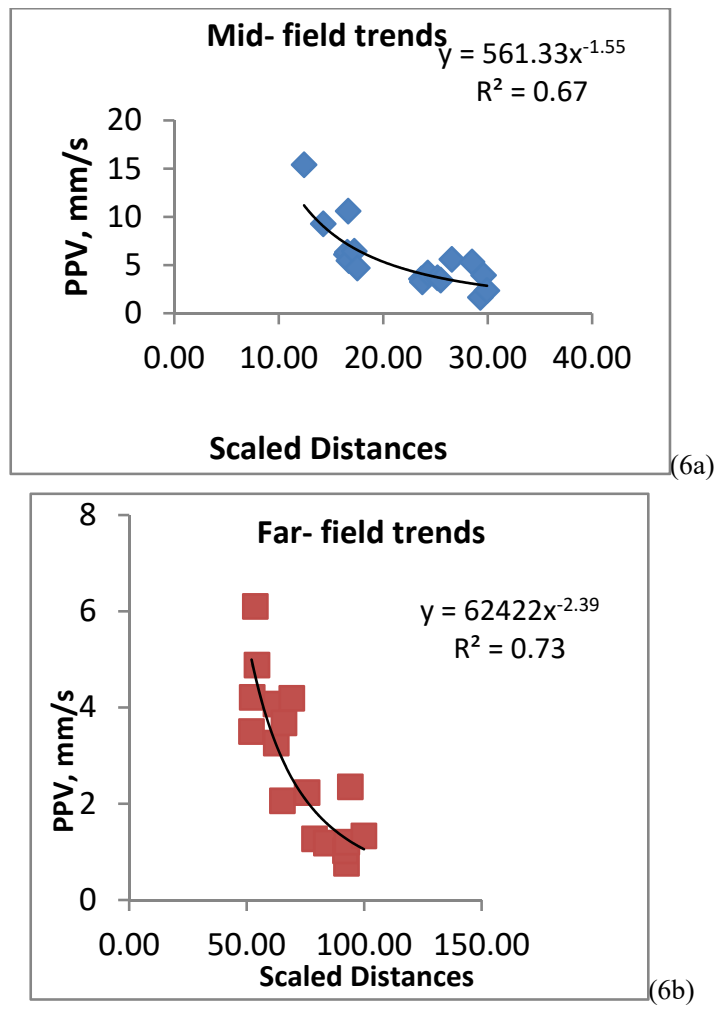

Fig 6: Mid-field and Far-field ground vibration attenuation trends 

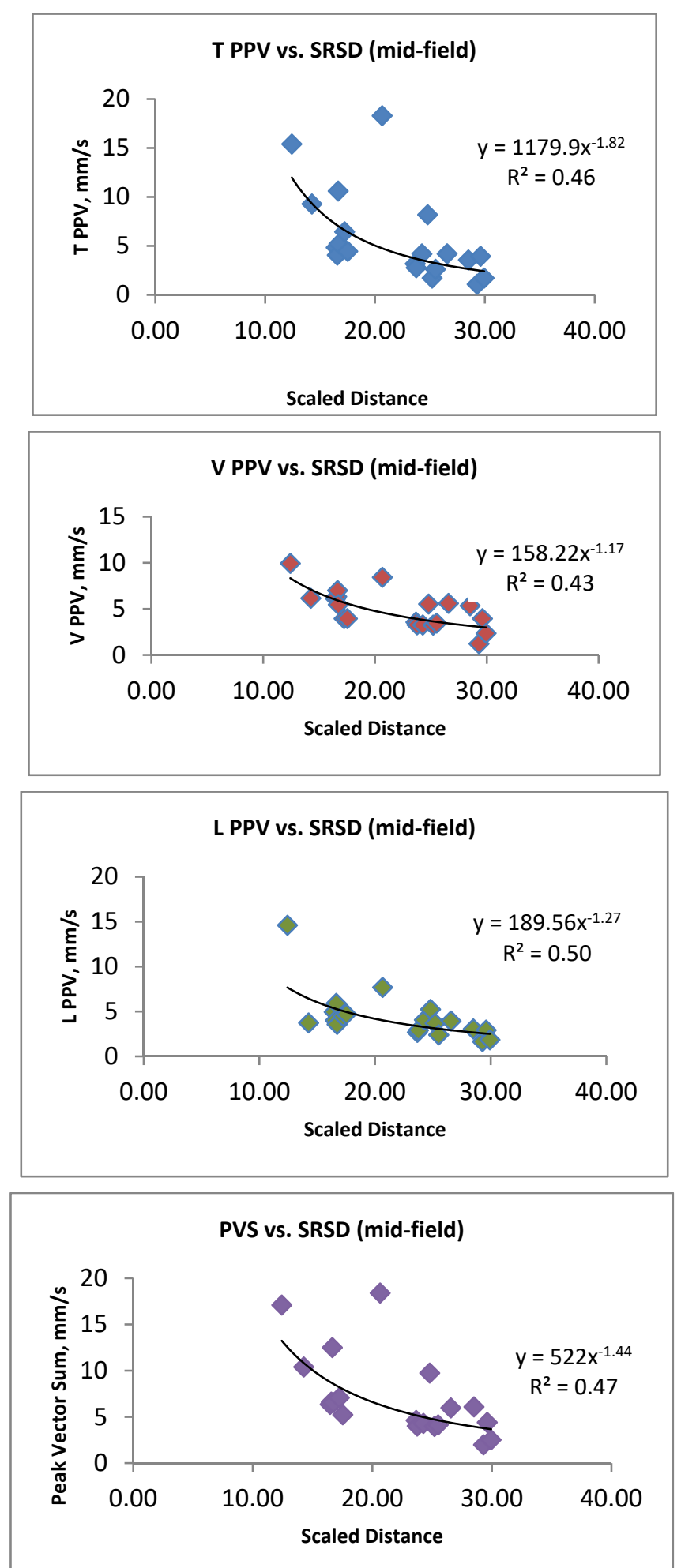

Fig 7: Mid-field trends of the various components of ground vibration and peak vector sum

\section{CONCLUSION}

The attenuation characteristics of ground vibrations are understood better for combined, far-field and mid-field observations. Since the maximum permissible charge per
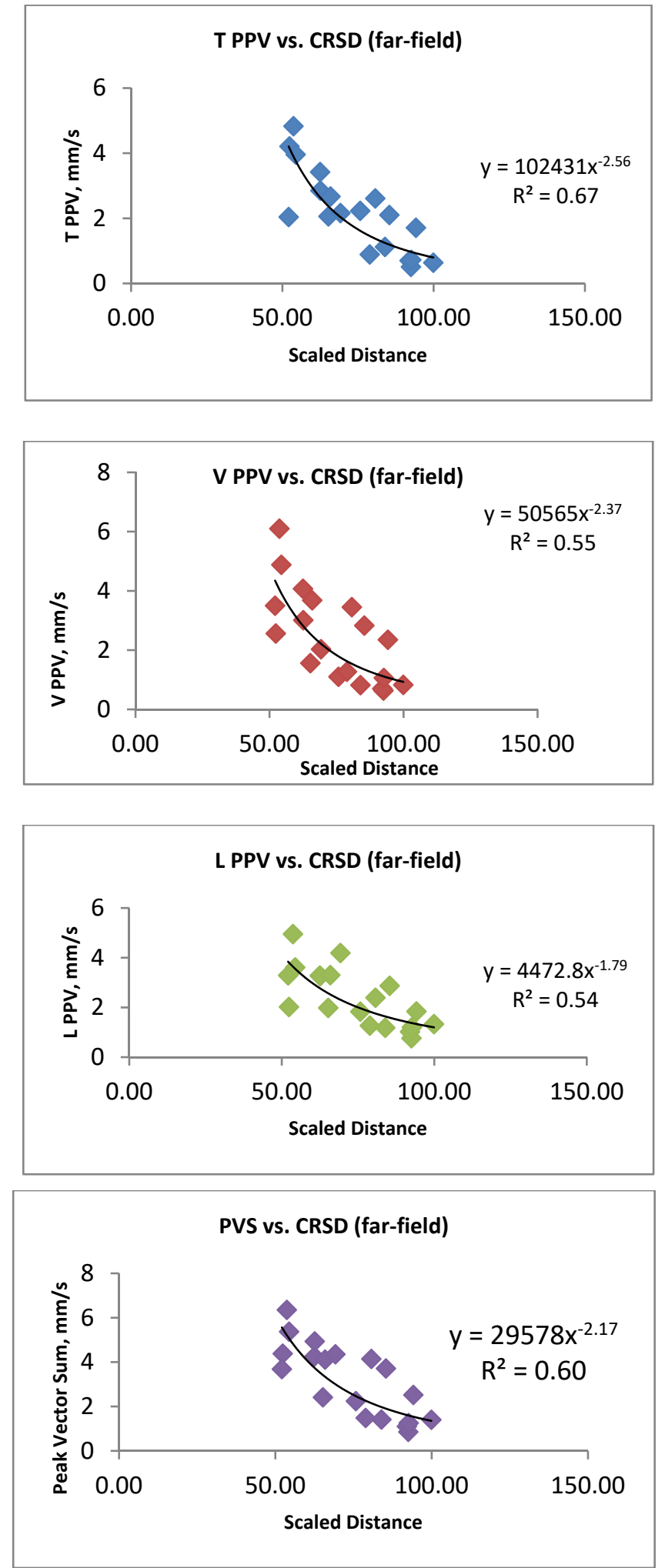

Fig 8: Far-field trends of the various components of ground vibration and peak vector sum against scaled distance

delay is calculated from the attenuation characteristic, this assumes importance. It was found that the mid-field equation yields lower values of maximum charge per delay which is important from safety view point when quarry lines 
approach human dwellings $(<30 \mathrm{SD})$. For Scaled Distance (SD) values more than 30 , the combined equation will hold good. The discussion about bench stiffness and geometrical attenuation show that these parameters need to be addressed in greater detail to appreciate a wholesome picture about vibration attenuation.

\section{REFERENCES}

[1] N.R Ambraseys and A. J. Hendron, "Dynamic behavior of rock masses", Rock Mechanics in Engineering Pracices, London Wiley pp 203-207, 1968

[2] R. L. Ash,"The influence of geological discontinuities on rock blasting". Ph.D. thesis, Department of Civil and Mineral Engineering, University of Minnesota, St. Paul, Minnesota. Pp 289, 1973

[3] R. L.Ash, "Blasting Characteristics of large diameter boreholes", $6^{\text {th }}$ Annual Drilling and Blasting Technology, Houston, 1977

[4] Bureau of Indian Standard, "Criteria for safety and design of structures subjected to underground blast", ISI Bulletin, IS-6922, 1973

[5] A. K.Chakraborty et al,"Innovative Cautious blasting technique for excavation close to a running hydro-electric powerhouse- a case studyProceedings of the Institution of Civil Engineers- Geotechnical Engineering, pp 62, 1996

[6] C. H. Dowding,"Blast Vibration Monitoring and Control SWETS, $1{ }^{\text {st }}$ Ed1994

[7] W.I.Duvall and D.E.Fogelson,"Review of criteria for estimating damage to residences from blasting vibrations,"USBM-RI5968, 1962

[8] A.Ghosh and J.K. Daemen,"A simple new blast vibration predictorbased on wave propagation laws," $24^{\text {th }}$ US Symposium on Rock Mechanics, 1983

[9] R.Holmberg and P-APersson,"The Swedish approach to contour blasting,"Proceedings of the $4^{\text {th }}$ conference on Explosives and Blasting technique. SEE, pp 113-127, 1978.

[10] W. A. Hustrulid,"Blasting Principles for Open pit mining,"CRC Press, Vol.2,1999.

[11] U. Langefors and B. Kihlstrom, "The Modern Technique of Rock Blasting," $3^{\text {rd }}$ Ed., Halsted Press, a Division of john Wiley \& Sons Inc., New York, pp 438, 1978

[12] P. P. Roy,"Vibration control in an open cast mine based on improved blast vibration predictors,"Mining Science and technology, The Netherlands, Vol. 12, pp 157-165,1991.

[13] P.P. Roy,"Rock Blasting Effects and Operations," CRC Press, 2005

[14] J. F.Wiss,P.W.Linehan, "Control of vibrations and Blast Noise from surface coal mining,"Research report for the U.S. Bureau of Mines, Contract 10255022,1978.

C. L. Jimeno, E. L. Jimeno and F.J.A. Carcedo, " Drilling and Blasting of rocks, ” A. A. Balkema, Rotterdam, Brookfield, 1995. 